Dr PHILIP CASS is reviews editor of Pacific Journalism Review.

\section{Maintaining the climate struggle}

An Inconvenient Sequel: Truth to Power. directed by Bonni Cohen, John Shenk. 2017. Running time: 98min.

A $n$ Inconvenient Sequel picks up a decade after the powerful and passionate An Inconvenient Truth introduced us to Al Gore's crusade to make people behave responsibly over climate change.

In this film Gore, once nearlypresident of the United States, Nobel laureate and Oscar winner, has emerged as the elder statesman of the climate change movement, inspiring legions of followers across the world and intervening during the Paris climate talks to secure a deal with India.

His speeches and his activism are inspiring, but in many ways this is more of a film about Gore than about climate change.

Perhaps the filmmakers thought that people knew the basic facts and didn't need to be reminded.

This means that people who have not seen the first film, or are new to the climate change issue as many younger viewers may be, may find themselves a little adrift.

The film inadvertently brings in broader issues of global change into focus when a live broadcast is cancelled because of the 2015 terrorist attacks

\section{aninconvenientsequel}

TRUTH TO POWER

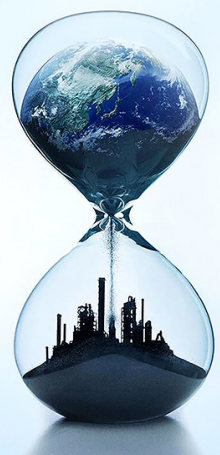

on Paris, but takes the link no further.

However, as the 2016 documentary Age of Consequences showed, the links between climate change, globalisation and terrorism, are now becoming clear.

There are also one or two moments in the film - the meeting with Canadian Prime Minister Justin Trudeau among them-which do not appear to be entirely, shall we say, spontaneous.

This is not to say that An Inconvenient Sequel is a bad film. It's not and it deserves an audience.

At the end of the film, Gore gives an impassioned speech in which he compares the climate change struggle with the civil rights movement. With a savage in the White House, taking inspiration from the beliefs and hopes of the civil rights movement may well be vital to maintaining the struggle to keep climate change under control before it is too late.

\section{Reference}

Age of Consequences (2016). Directed by Jared P. Scott [Documentary]. 80min. 